\title{
Kinetic, Mechanistic, and Thermodynamic Studies for Oxidation of L-Alanine by Alkaline Sodium Periodate in Presence of Os(VIII) in its Nano Concentration Range as Homogenous Catalyst
}

\author{
Madhu Gupta $^{1}$, Amrita Srivastava ${ }^{1, *}$ Sheila Srivastava ${ }^{2}$ \\ ${ }^{1}$ Department of Chemistry University of Lucknow, Lucknow, Uttar Pradesh, India \\ ${ }^{2}$ Chemical Laboratories Feroze Gandhi College, Raebareli, Uttar Pradesh, India
}

Received: $11^{\text {st }}$ October 2017; Revised: $11^{\text {st }}$ February 2018; Accepted: $18^{\text {th }}$ February 2018; Available online: $11^{\text {st }}$ June 2018; Published regularly: $1^{\text {st }}$ August 2018

\begin{abstract}
The kinetics and mechanism of homogenously Os(VIII) catalysed oxidation of L-alanine (L-ala) by alkaline sodium periodate in temperature range 30 to $45^{\circ} \mathrm{C}$ have been studied. The involvement of free radicals was observed in the reactions. The oxidation products were acetaldehyde and $\mathrm{IO}_{3}$, identified by spot test and spectroscopic studies. The stoichiometry between [L-ala]: $\mathrm{IO}_{4}$ - is 1:2. The reaction show negligible effect of mercuric acetate and ionic strength of medium. The experimental results show first order in oxidant $\left[\mathrm{NaIO}_{4}\right]$ and negative effect of $[\mathrm{OH}]$. The order in $[\mathrm{Os}(\mathrm{VIII})]$ as well as L-alanine was unity. A mechanism involving the formation of complex between L-alanine and Os(VIII) was proposed. The reaction constants concerned in the different steps of mechanism were calculated at different temperature. The activation parameters for the slow step of mechanism were computed and discussed. The thermodynamic quantities were also calculated for the reaction. Copyright () 2018 BCREC Group. All rights reserved
\end{abstract}

Keywords: Sodium Periodate; Kinetics; L-alanine; Os(VIII) Catalysis; Oxidation

How to Cite: Gupta, M., Srivastava, A., Srivastava, S. (2018). Kinetic, Mechanistic, and Thermodynamic Studies for Oxidation of L-Alanine by Alkaline Sodium Periodate in Presence of Os(VIII) in its Nano Concentration Range as Homogenous Catalyst. Bulletin of Chemical Reaction Engineering \& Catalysis, 13 (2): 355-364 (doi:10.9767/bcrec.13.2.1583.355-364)

Permalink/DOI: https://doi.org/10.9767/bcrec.13.2.1583.355-364

\section{Introduction}

From last few years, the study of transition metals with high oxidation state has attracted many researchers because such metals produce stable complexes with appropriate polydentate ligand. The application of transition metal ions such as osmium, ruthenium and iridium, either alone or in mixtures, acts as catalysts for differ-

* Corresponding Author.

E-mail: amrita.sri18@gmail.com (A. Srivastava) ent redox processes [1]. The importance of Os(VIII) as a catalyst has been noticed in some redox reactions $[2,3]$. Osmium form stable compounds in +8 oxidation state. The $\mathrm{OsO}_{4}$ [Os(VIII)] also gives reduction up to +2 via +4 and +6 oxidation state in acid medium. However, if the medium is alkaline, it gives reduction up to +6 oxidation state only [4]. The exclusive nature and most favourable reduction potential, [5] of $\mathrm{Os}(\mathrm{VIII}) / \mathrm{Os}(\mathrm{VI})$ of $+0.85 \mathrm{~V}$ in acid medium and $+0.30 \mathrm{~V}$ in alkaline medium helps it to act as catalyst with different oxidants in 
oxidation of substrates whether they are organic or inorganic [6]. The literature survey reveals that the catalytic role of osmium(VIII) is well recognized.

Oxidation reactions have its own importance and are key alteration in organic synthesis [7]. Oxidation of amino acids plays a significant role [8]. The dehydrogenation of amino acids by flavoenzymes has involved researchers in last few years. Oxidation of amino acids has been done by variety of oxidizing agents [10]. The Lalanine (L-ala) is chemically known as (2S)-2aminopropanoic acid. In essence it occurs in poultry, beef, pork and fish. Majority of animal based protein sources have abundance of L-ala. L-ala levels increases within body during muscle contraction. It is used by the body as a fundamental block of protein. L-ala has paramount role in transfer of nitrogen from tissue sites in the body to liver. It act as source of energy to brings forth blood sugar in human body [11].

Periodate is very discriminating and immaculate reagent for oxidative cleavage of organic compounds containing amino, $a$-hydroxy, oxo or carboxyl groups [12]. Oxidation with periodate causes denaturation of proteins and deterioration of enzymes and these findings have been elucidated on the basis of reaction of essential amino acids with periodate [13]. The nature of substrate, the oxidant and experimental conditions influence the mechanism of catalysis. It has been made known [14] that as catalyst metals act among one of these paths such as oxidation of substrate, complex with reactants or free radicals formation. The authors have experienced that osmium in microamount catalyzes the oxidation of L-ala by sodium periodate in alkaline medium. To comprehend the active species of oxidant and catalyst and for shaping the suitable mechanism, the title reaction is investigated thoroughly to understand all mechanistic prospective. This mechanism perceptive allows chemistry to be interpreted.

\section{Materials and Method}

\subsection{Materials and reagents}

All the chemicals were of reagent grade and double distilled water was used during the experiment. A solution of L-ala (E. Merck) was prepared in double distilled water. The purity of L-ala sample was confirmed by its melting point $312{ }^{\circ} \mathrm{C}$ (Lit. m.p $314{ }^{\circ} \mathrm{C}$ ). The necessary concentration of L-ala was prepared from its stock solution. The osmium solution was made by dissolving $\mathrm{OsO}_{4}$ (Johnson Mathey) in 0.50 mol.dm-3 $\mathrm{NaOH}$. The concentration was estab- lished [15] by elucidating unreacted $\left[\mathrm{Fe}(\mathrm{CN})_{6}\right]^{4-}$ with standard $\mathrm{Ce}(\mathrm{IV})$ solution in an acidic medium. For maintaining ionic strength and alkalinity of reaction, $\mathrm{KClO}_{3}$, and $\mathrm{NaOH}$ were used, respectively. The standard solution of $\mathrm{NaIO}_{4}$ was equipped by dissolving its weighed amount in double distilled water. This solution was standardised against hypo solution which was already standardized against copper sulphate (B.D.H) solution. The improvement of reaction was followed iodometrically. Other reagents used were, A.R. grade and their solutions, were also prepared in doubly distilled water. The reaction vessels were black coated from exterior to avoid photochemical effects.

\subsection{Kinetic measurements}

The kinetic runs were carried out at $35^{\circ} \mathrm{C} \pm$ $0.1{ }^{\circ} \mathrm{C}$. The reaction was initiated by mixing the previously themostated solution of sodium periodate to the thermally equilibrated reaction mixture containing required volume of solution of L-ala, $\mathrm{Os}$ (VIII), $\mathrm{NaOH}$, and all other reagents. Aliquots $(5 \mathrm{ml})$ of the reaction mixture were taken out at definite intervals of time and poured into a volumetric flask containing $5 \mathrm{ml}$ of dil. $\mathrm{H}_{2} \mathrm{SO}_{4}$ and $5 \mathrm{ml}$ of $4 \% \mathrm{KI}$ solution. The amount of iodine liberated is equivalent to unconsumed oxidant which was estimated with standard sodium thiosulphate solution using starch as an indicator. The initial rates were estimated from the slope of concentration vs. time graph in the initial stages of the reactions by plane mirror method. The rate constants were reproducible to within $\pm 5 \%$.

\section{Result and Discussion}

\subsection{Stoichiometry and product analysis}

To ascertain the stoichiometry of the reaction, different sets of experiments with various ratios of $\left[\mathrm{NaIO}_{4}\right]$ :[L-ala] were performed at 35 ${ }^{\circ} \mathrm{C}$ for 48 hours and keeping concentration of all other reactants constant under conditions $\left[\mathrm{NaIO}_{4}\right]>>$ [L-ala]. The unconsumed amount of periodate estimated in different sets shows that 2 moles of $\mathrm{NaIO}_{4}$ was consumed to oxidize 1 mole of L-ala. In stoichiometry and product analysis, scheme 1 is stated for reaction. Accordingly the following stoichiometric equation can be formulated in Scheme 1 .

The stoichiometric ratio propose that the main product was acetaldehyde, which was recognized by chromatography (TLC), conventional method (spot test) [16] and also by 2,4dinitrophenyl hydrazine (DNPH) derivative 
(Brady's test). The product was also confirmed by its FT-IR spectrum showing a carbonyl stretching at $1729 \mathrm{~cm}^{-1}$ and $-\mathrm{CH}$ stretching at $2730 \mathrm{~cm}^{-1}$ and $-\mathrm{CH}$ bending at $1370 \mathrm{~cm}^{-1}$ (Figure 1). Carbon dioxide was qualitatively detected by aerated $\mathrm{N}_{2}$ gas through the acidified reaction mixture and passing a librated gas through a tube containing lime water. Ammonia was recognized by Nessler reagent [17]. The aldehyde was confirmed by preparing 2,4-DNP derivative [18]. The product didn't undergo oxidation further under these kinetic conditions.

\subsection{Reaction orders}

The reaction order have been determined from the slope of log [conc.] vs. log $d c / d t$ plots by changing the concentrations of L-ala, alkali, periodate, Os(VIII) and mercuric acetate in turn while maintaining all other concentrations and conditions constant. The order in periodate was unity between the concentration range of $0.83 \times 10^{-3}$ to $5.0 \times 10^{-3}$ mol. $\mathrm{dm}^{-3}$ at fixed concentrations of $\mathrm{Os}(\mathrm{VIII}), \mathrm{NaOH}$, and $\mathrm{KClO}_{3}$. Linear- ity of the plots of $d c / d t$ vs. time till $80 \%$ completion of reaction indicates a reaction order of unity in periodate (Figure 2). The first order dependence was also confirmed from the plot of $\log \left[\mathrm{NaIO}_{4}\right]$ vs. $\log d c / d t(r \geq 0.99336, S \leq$ 0.0977) (Figure 6).

The effect of L-ala on the rate of reaction was deliberated at constant concentrations of alkali, Os(VIII) and periodate at a constant ionic strength of $0.005 \mathrm{~mol}^{-\mathrm{dm}^{-3}}$. The L-ala concentration was wide-ranging between $0.13 \times 10^{-2}$ to $2.0 \times 10^{-2}$ mol.dm ${ }^{-3}$ at $35^{\circ} \mathrm{C}$ while keeping other reactant concentrations and conditions constant $(r \geq 0.98286, \mathrm{~S} \leq 0.0 .2023)$ (Figure 5). The value of $\mathrm{k}_{1}$ increases on rising the concentration of [L-ala] signifying a less than unit order dependency on [L-ala]. The effect of alkali on the reaction has been considered in the range of $0.83 \times 10^{-3}$ to $5.0 \times 10^{-3} \mathrm{~mol} \mathrm{dm}^{-3}$ at fixed concentrations of Os(VIII), L-ala, periodate and $\mathrm{Hg}(\mathrm{OAc})_{2}$ at constant ionic strength 0.005 mol.dm ${ }^{-3}$ (Figure 6). The rate constants decreased with increase in alkali concentration,

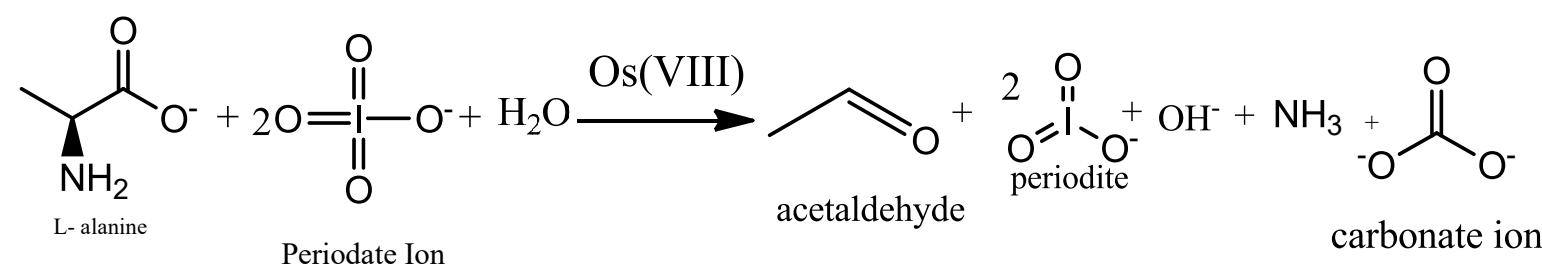

Scheme 1. Scheme showing chemical reaction and stoichiometry of oxidation of L-ala by alkaline sodium periodate

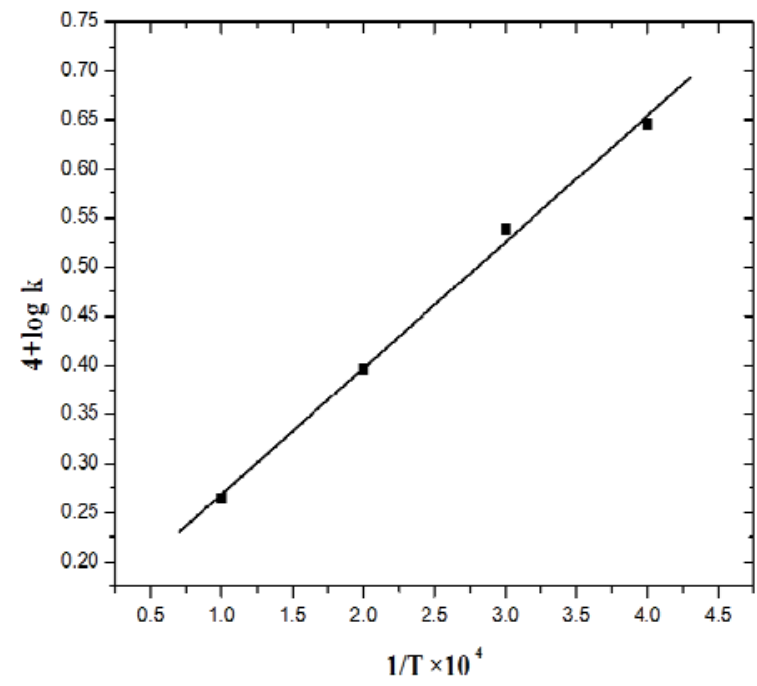

Figure 1. Effect of temperature on rate constant for oxidation of L-ala at $308 \mathrm{~K}$. $\left[\mathrm{NaIO}_{4}\right]$ $=1.0 \times 10^{-3} \mathrm{~mol} . \mathrm{dm}^{-3} ;[\mathrm{L}-\mathrm{ala}]=1.0 \times 10^{-2} \mathrm{~mol} . \mathrm{dm}^{-3}$; $\mathrm{Os}(\mathrm{VIII})=2.6 \times 10^{-6} \mathrm{~mol} . \mathrm{dm}^{-3} ;[\mathrm{NaOH}]=1.0 \times 10^{-3}$ mol.dm ${ }^{-3} ;\left[\mathrm{Hg}(\mathrm{OAc})_{2}\right]=1.25 \times 10^{-3} \mathrm{~mol} \mathrm{dm}^{-3}$

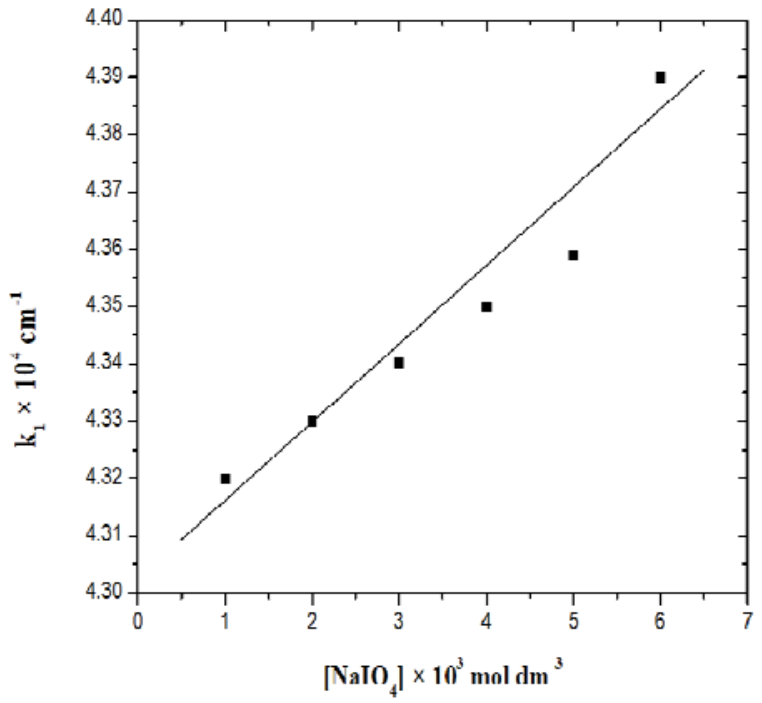

Figure 2. Plot between rate constant vs. $\left[\mathrm{NaIO}_{4}\right]$ for oxidation of L-ala at $308 \mathrm{~K}$. [L-ala] $=1.0 \times 10^{-2}$ mol. $\mathrm{dm}^{-3} ; \quad$ Os(VIII) $=2.6 \times 10^{-6}$ mol.dm ${ }^{-3} ;[\mathrm{NaOH}]=1.0 \times 10^{-3} \quad \mathrm{~mol}^{-\mathrm{dm}^{-3}}$; $\left[\mathrm{Hg}(\mathrm{OAc})_{2}\right]=1.25 \times 10^{-3} \mathrm{~mol} . \mathrm{dm}^{-3}$ 
demonstrating negative fractional order dependence of rate on alkali concentration.

\subsection{Effect of added products}

The effect of initially added products $\mathrm{IO}_{3}$ and acetaldehyde were considered in concentration range $8.0 \times 10^{-4}$ to $5.0 \times 10^{-3} \mathrm{~mol} . \mathrm{dm}^{-3}$ at fixed concentration of oxidant, alkali, reductant, and catalyst. It is found that both added products did not affect the reaction rate.

\subsection{Effect of ionic strength (I) and dielec- tric constant (D)}

The ionic strength was studied by using $\mathrm{KClO}_{3}$ in concentration range between 0.1 to $0.9 \mathrm{~mol}_{\mathrm{dm}} \mathrm{d}^{3}$ at constant concentrations of alkali, oxidant, reductant and catalyst at $35^{\circ} \mathrm{C}$.

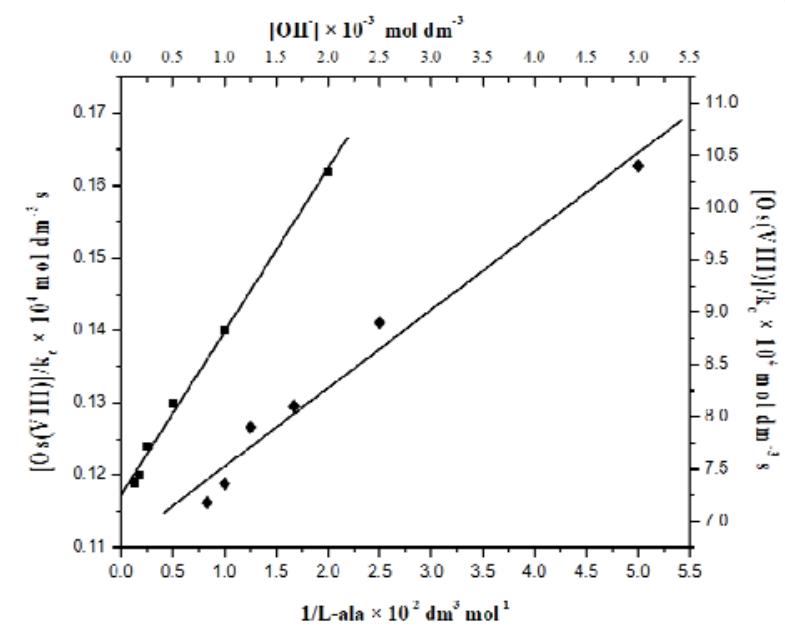

Figure 3. Verification of rate law (4) in form of (5) for Os(VIII) catalyzed oxidation of L-alanine by sodium periodate at $25^{\circ} \mathrm{C}$.

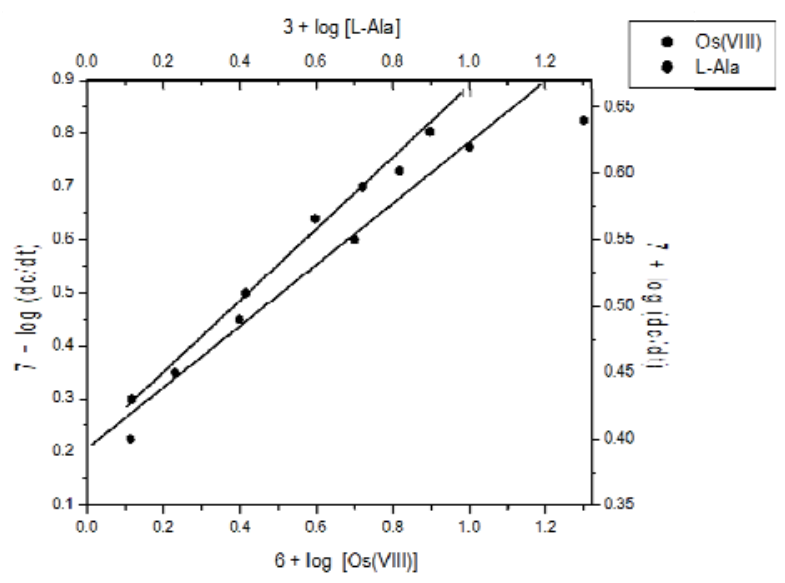

Figure 5. Plot between rate log $[\mathrm{Os}(\mathrm{VIII})]$ vs. $\log (d c / d t)$ and $\log$ [L-Ala] vs $\log (d c / d t)$ for oxidation of L-ala at $308 \mathrm{~K}$.
Similarily, dielectric constant of the medium D was varied using $\mathrm{CH}_{3} \mathrm{COOH}$ and $\mathrm{H}_{2} \mathrm{O}$ in different ratios. As result of experiment we come to know that both had no noteworthy effect on the rate of reaction.

\subsection{Test for free radicals (Polymerisation study)}

The participation of free radicals for Os(VIII) catalysed reactions was experienced. The reaction mixture was tested with acrylonitrile monomer and was reserved for 2 hours in an inert atmosphere. On diluting with methanol, reaction mixture gives a white precipitate which indicates the union of free radicals. The blank experiments of periodate or L-ala alone with acrylo nitrile didn't give any polymerisation under similar conditions. Primarily added

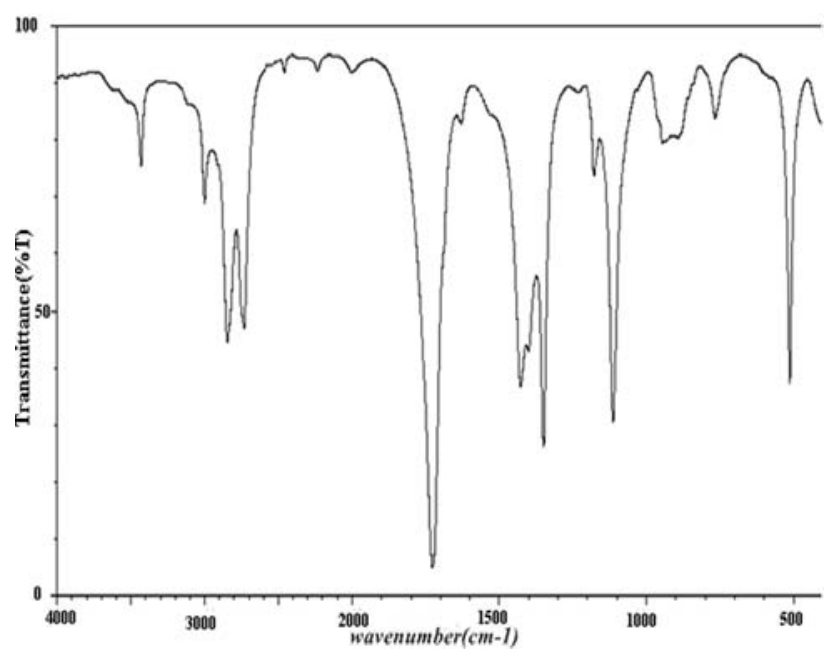

Figure 4. FT-IR spectrum of final product

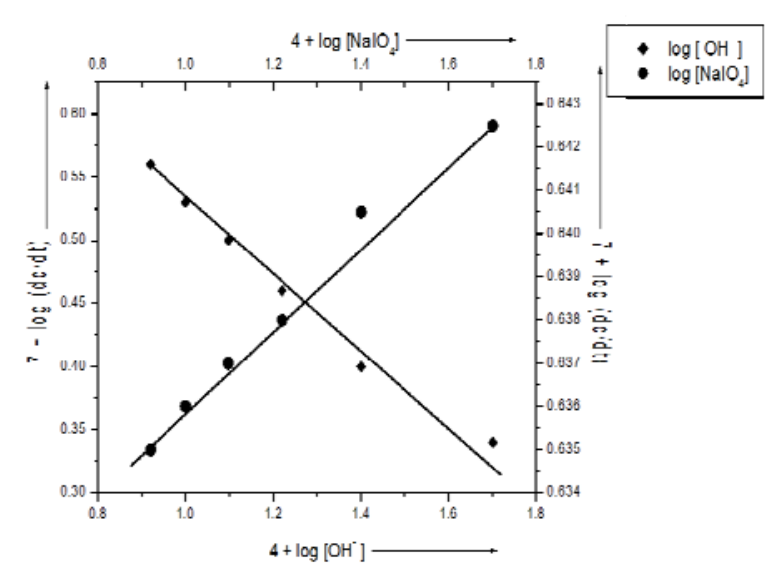

Figure 6. Plot between $\log \left[\mathrm{OH}^{-}\right]$vs.log $(d c / d t)$ and $\log \left[\mathrm{NaIO}_{4}\right]$ vs $\log (d c / d t)$ for oxidation of Lala at $308 \mathrm{~K}$. 
acrylonitrile decreased the rate of reaction which is a function of free radicals.

\subsection{Effect of temperature}

The consequence of temperature for Os(VIII) catalysed oxidation was studied at $30,35,40$, and $45{ }^{\circ} \mathrm{C}$. The rate constants, $\left(k_{2}\right)$, of the slow step of Scheme 1 were obtained from the slopes and the intercepts of the plots of $[\mathrm{Os}(\mathrm{VIII})] / k_{1}$ vs. 1/[L-ala] at four different temperatures. The values specified in Table 2 were used to estimate the activation parameters. The energy of activation analogous to these constants was evaluated from the Arrhenius plot of $\log k$ vs. $1 / T$ (Figure1) and other activation parameters obtained are tabulated in Table 2.

\subsection{Effect of [Os(VIII)]}

The $[\mathrm{Os}(\mathrm{VIII})]$ concentration was wideranging from $1.31 \times 10^{-6}$ to $7.88 \times 10^{-6} \mathrm{~mol} . \mathrm{dm}^{-3}$, at set concentrations of $\mathrm{NaOH}$, L-ala, periodate, $\mathrm{Hg}(\mathrm{OAc})_{2}$, and ionic strength. The order in [Os(VIII)] was establish to be unity from the linearity of plots of $\log [\mathrm{Os}(\mathrm{VIII})]$ vs. $\log (d c / d t)$ (Figure 5).

In aqueous alkaline medium and at high temperature, periodate exists as $\mathrm{HIO}_{6}{ }^{4-}$ [19]. Periodic acid exists as $\mathrm{H}_{5} \mathrm{IO}_{6}$ and as $\mathrm{H}_{4} \mathrm{IO}_{6}$. around $\mathrm{pH}$ 7. Therefore in alkaline medium, the main species exist as $\mathrm{IO}_{4}^{-}, \mathrm{H}_{3} \mathrm{IO}_{6}{ }^{2-}$, and $\mathrm{H}_{2} \mathrm{IO}_{6}{ }^{3-}$ (Scheme 2). As the concentration increases, periodate also try to form a dimmer [20]. In the majority of papers [21], on oxidation, periodate decreases and $\mathrm{OH}-$ enhances the rate of reaction. But in present study, absolutely different results have been obtained. Since $\mathrm{OH}-$ retards the rate of reaction (Table 1 ).

It is well-known that L-ala is present in form of zwitterions [22] in aqueous medium (Scheme 3). In extremely acidic medium, it exists in protonated form while in alkaline medium it is present as anionic form (Scheme 3).

The Os(VIII) exist as different complexes in different $\mathrm{OH}^{-}$[23] concentrations, such as: $\left[\mathrm{OsO}_{4}(\mathrm{OH})_{2}\right]^{2-}$ and $\left[\mathrm{OsO}_{5}(\mathrm{OH})\right]^{3}$. As $\mathrm{OH}$ concen-

$$
\left\{\begin{array}{l}
\mathrm{H}_{5} \mathrm{IO}_{6} \rightleftharpoons \mathrm{H}_{4} \mathrm{IO}_{6}^{-}+\mathrm{H}^{+} \\
\mathrm{H}_{4} \mathrm{IO}_{6}{ }^{-} \rightleftharpoons \mathrm{IO}_{4}^{-}+2 \mathrm{H}_{2} \mathrm{O} \\
\mathrm{H}_{4} \mathrm{IO}_{6} \mathrm{H}_{3} \mathrm{HO}_{6}{ }^{2-}+\mathrm{H}^{+} \\
\mathrm{H}_{3} \mathrm{IO}_{6}{ }^{2} \rightleftharpoons \mathrm{H}_{3} \mathrm{IO}_{6}{ }^{3-}+\mathrm{H}^{+}
\end{array}\right\}
$$

Scheme 2: Various forms of periodate in different medium tration increases the role of $\left[\mathrm{OsO}_{5}(\mathrm{OH})\right]^{3-}$ is noteworthy. As in case of current work, the concentration of $\mathrm{OH}^{-}$decreases, it is logical that $\left[\mathrm{OsO}_{5}(\mathrm{OH})_{2}\right]^{2-}$ was active species and its formation is significant in reaction (Scheme 4). Anionic structure of L-ala reacts with Os(VIII) active species to construct a complex $\left[\mathrm{C}_{3}\right]$, which further react with one mole of periodate in slow step to turn out a free radical of L-ala, $\mathrm{IO}_{3}$ - with regeneration of catalyst, Os(VIII). Additionally this free radical of L-ala react with one mole of periodate in fast step to provide products as given in Scheme 4. The probable structure of the complex $\left[\mathrm{C}_{3}\right]$ is given below:

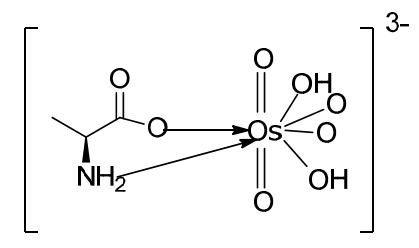

The spectroscopic evidence for formation of complex between catalyst and substrate was

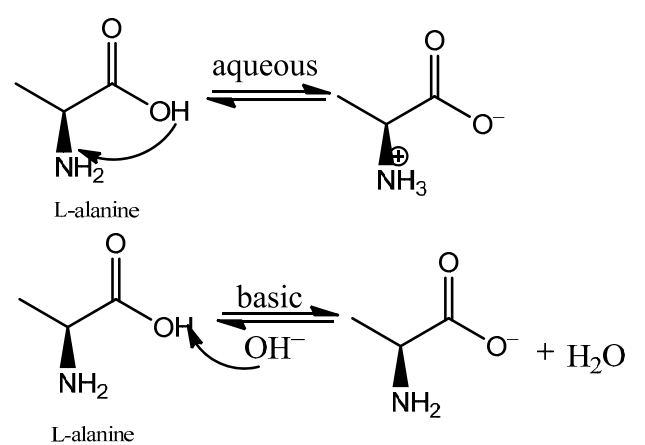

Scheme 3: Scheme showing zwitterions of L-ala

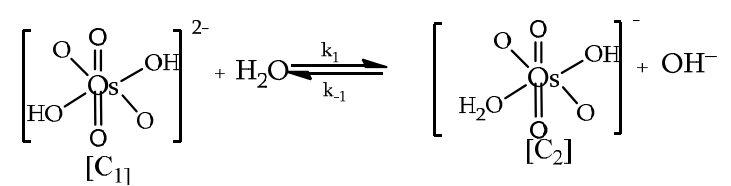

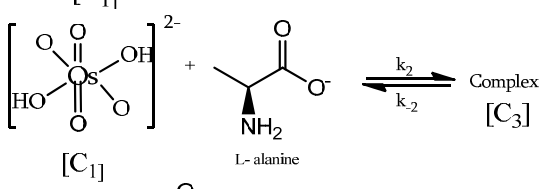

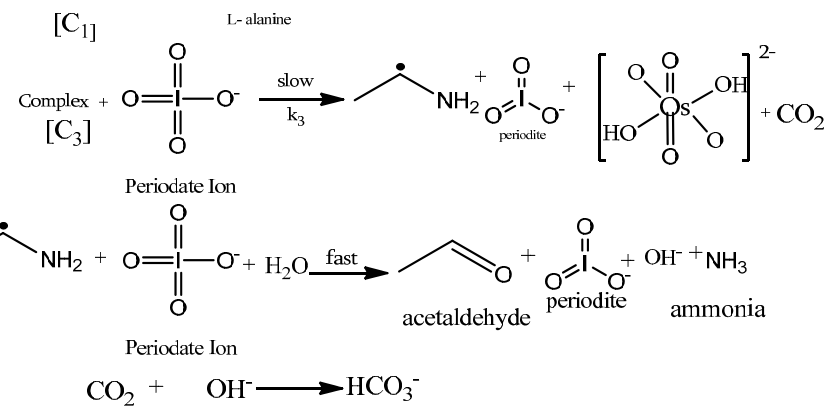

Scheme 4. Detail scheme for the Os(VIII) catalysed oxidation of L-alanine by alkaline sodium periodate 
obtained from UV-Vis spectra of L-ala $\left(1.0 \times 10^{-2}\right.$ mol.dm $\left.{ }^{-3}\right)$, Os(VIII) $\left(2.6 \times 10^{-6} \mathrm{~mol}_{\mathrm{dm}}^{-3}\right),\left[\mathrm{OH}^{-}\right]$ $\left(1.0 \times 10^{-3}\right.$ mol.dm $\left.{ }^{-3}\right)$ and mixture of both. A hypsochromic shift of about $7 \mathrm{~nm}$ from $292 \mathrm{~nm}$ of L-ala to $285 \mathrm{~nm}$ of mixture of Os(VIII) and Lala was observed. The Lineweaver-Burk plot proved the complex formation between Os(VIII) and L-ala, which explains fractional order in [L-ala]. The rate law for Scheme 4 is derived as:

$$
\begin{aligned}
& \text { Rate }=\frac{d\left[\mathrm{IO}_{4}^{-}\right]}{d t} \\
& \text { Rate }=\left\{\frac{k_{3} K_{2}\left[\mathrm{IO}_{4}^{-}\right]\left[\mathrm{Os}(\mathrm{VIII})_{T}\right][L-\text { ala }]}{1+K_{1}[\mathrm{OH}-]+K_{2}[L-\text { ala }]}\right\} \\
& k=\frac{\text { Rate }}{\left[\mathrm{IO}_{4}^{-}\right]}=\left\{\frac{k_{3} K_{2}\left[\mathrm{OS}(\mathrm{VIII})_{\mathrm{T}}\right][L-\text { ala }]}{1+K_{1}\left[\mathrm{OH}^{-}\right]+K_{2}[L-\text { ala }]}\right\}
\end{aligned}
$$

The rate law (3) can be rearranged to equation (4), which is suitable for verification.

$$
\frac{\left[\mathrm{Os}(\mathrm{VIII})_{T}\right]}{k}=\frac{1}{k_{3} K_{2}[L-a l a]}+\frac{K_{1}\left[\mathrm{OH}^{-}\right]}{k_{3} K_{2}[L-a l a]}+\frac{1}{k_{3}}
$$

Equation (4) proves that, the plots of $[\mathrm{Os}(\mathrm{VIII})] / k$ vs. $1 /[\mathrm{L}-\mathrm{ala}]$ and $[\mathrm{Os}(\mathrm{VIII})] / k$ vs. [OH-] were linear (Figure 3). A van't Hoff's plot was prepared for the deviation of $\mathrm{k}$ with temperature [i.e. log $k$ versus $1 / T$ ] (Figure 1) and the values of the enthalpy of reaction $\Delta \mathrm{H}$, entropy of reaction $\Delta S$ and free energy of reaction $\Delta G$ were calculated. These values are also specified in Table 2. Insignificant effect of ionic strength and dielectric constant in catalyzed reaction might be due to contribution of neutral species in the reaction (Schemes 2). The negative value of $\Delta S^{\#}$ suggests that the intermediate complex is more ordered than the reactants [24]. The observed modest enthalpy of activation and an elevated rate constant for the slow step point towards the fact that the oxidation most probably occurs via an inner sphere mechanism. This conclusion is supported by a

\begin{tabular}{|c|c|c|c|c|c|c|}
\hline $\begin{array}{l}{\left[\mathrm{NaIO}_{4}\right] \times 10^{3}} \\
\left(\mathrm{~mol}_{\mathrm{dm}}^{-3}\right)\end{array}$ & $\begin{array}{c}{[\mathrm{S}] \times 10^{2}} \\
\left(\mathrm{~mol} . \mathrm{dm}^{-3}\right)\end{array}$ & $\begin{array}{l}\mathrm{Os}(\mathrm{VIII}) \times 10^{-6} \\
\quad\left(\mathrm{~mol} . \mathrm{dm}^{-3}\right)\end{array}$ & $\begin{array}{l}{[\mathrm{NaOH}] \times 10^{3}} \\
\left(\mathrm{~mol} . \mathrm{dm}^{-3}\right)\end{array}$ & $\begin{array}{l}{\left[\mathrm{Hg}(\mathrm{OAc})_{2}\right] \times 10^{3}} \\
\quad\left(\mathrm{~mol} . \mathrm{dm}^{-3}\right)\end{array}$ & $\begin{array}{c}(-d c / d t) \times 10^{7} \\
\left(\mathrm{~mol}^{-} \mathrm{dm}^{-3} \mathrm{~s}^{-1}\right) \\
\text { Leucine }\end{array}$ & $\begin{array}{l}K_{1} \times 10^{2} \\
\text { (Observed) }\end{array}$ \\
\hline 0.83 & 1.00 & 2.6 & 1.00 & 1.25 & 2.34 & 4.32 \\
\hline 1.00 & 1.00 & 2.6 & 1.00 & 1.25 & 2.49 & 4.33 \\
\hline 1.25 & 1.00 & 2.6 & 1.00 & 1.25 & 3.00 & 4.34 \\
\hline 1.67 & 1.00 & 2.6 & 1.00 & 1.25 & 4.34 & 4.35 \\
\hline 2.50 & 1.00 & 2.6 & 1.00 & 1.25 & 4.65 & 4.37 \\
\hline 5.00 & 1.00 & 2.6 & 1.00 & 1.25 & 5.00 & 4.39 \\
\hline 1.00 & 1.00 & 1.31 & 1.00 & 1.25 & 2.28 & 2.39 \\
\hline 1.00 & 1.00 & 3.94 & 1.00 & 1.25 & 2.67 & 4.45 \\
\hline 1.00 & 1.00 & 5.25 & 1.00 & 1.25 & 2.73 & 4.70 \\
\hline 1.00 & 1.00 & 6.56 & 1.00 & 1.25 & 3.00 & 5.36 \\
\hline 1.00 & 1.00 & 7.88 & 1.00 & 1.25 & 3.30 & 6.37 \\
\hline 1.00 & 0.13 & 2.6 & 1.00 & 1.25 & 1.64 & 2.39 \\
\hline 1.00 & 0.17 & 2.6 & 1.00 & 1.25 & 1.71 & 3.08 \\
\hline 1.00 & 0.25 & 2.6 & 1.00 & 1.25 & 2.24 & 3.11 \\
\hline 1.00 & 0.50 & 2.6 & 1.00 & 1.25 & 2.40 & 3.93 \\
\hline 1.00 & 2.00 & 2.6 & 1.00 & 1.25 & 3.43 & 4.40 \\
\hline 1.00 & 1.00 & 2.6 & 0.83 & 1.25 & 2.50 & 3.62 \\
\hline 1.00 & 1.00 & 2.6 & 1.25 & 1.25 & 2.20 & 3.13 \\
\hline 1.00 & 1.00 & 2.6 & 1.67 & 1.25 & 2.00 & 2.70 \\
\hline 1.00 & 1.00 & 2.6 & 2.50 & 1.25 & 1.78 & 2.42 \\
\hline 1.00 & 1.00 & 2.6 & 5.00 & 1.25 & 1.25 & 2.31 \\
\hline 1.00 & 1.00 & 2.6 & 1.00 & 0.83 & 2.75 & 4.23 \\
\hline 1.00 & 1.00 & 2.6 & 1.00 & 1.00 & 2.40 & 3.83 \\
\hline 1.00 & 1.00 & 2.6 & 1.00 & 1.67 & 2.50 & 4.17 \\
\hline 1.00 & 1.00 & 2.6 & 1.00 & 2.50 & 3.20 & 5.16 \\
\hline 1.00 & 1.00 & 2.6 & 1.00 & 5.00 & 2.80 & 5.26 \\
\hline
\end{tabular}

Table 1. Effect of Variation of [ $\left.\mathrm{NaIO}_{4}\right]$, [L-ala], [OH-], [ $\left[\mathrm{IO}_{4} \cdot\right]$, and $[\mathrm{Os}(\mathrm{VIII})]$ on the Osmium(VIII) Catalysed Oxidation of L-alanine by sodium periodate in Aqueous Alkaline Medium at $298 \mathrm{~K}$ and I $=0.005$ mol.dm ${ }^{-3}$ 
former study [25]. The catalyst Os(VIII) forms the complex $\left(\mathrm{C}_{3}\right)$ with L-ala, which enhances the reducing assets of the substrate than that with no catalyst. Further, the catalyst Os(VIII) modifies the reaction pathway by lowering the energy of activation. The Os(VIII) catalyzed reaction, however, is logically fast in view of speediness of Os(VIII) to act across the $-\mathrm{COO}$ bond. Deviation in the rate within the reaction series may be caused by change in the enthalpy or entropy of activation.

\section{Conclusion}

Oxidation products were recognized. Among the variety of species of periodate in alkaline medium, $\mathrm{IO}_{4}$ - is considered to be the active species for the title reaction. Os(VIII) is found to be as $\left[\mathrm{OsO}_{4}(\mathrm{OH})_{2}\right]^{2-}$ as active species. Activation parameters were also calculated for slow step of reaction. Activation parameters and catalytic constants with respect to catalyst were also calculated. Without Os(VIII), the reaction between L-ala and sodium periodate is slow, whereas the addition of a small amount of Os(VIII) speedup the reaction due to formation of adduct between L-ala and osmium(VIII). As a catalyst, osmium(VIII) did not undergo reduction to Os(VI), but it catalyzes throughout the formation of active adduct and regenerates by reacting with $\mathrm{IO}_{4}$ in the rate determining step to give a free radical.

\section{Acknowledgement}

The authors are thankful to the Head, Department of Chemistry, University of Lucknow, Lucknow, for providing necessary laboratory facilities, spectral, elemental and biological activity data.

\section{References}

[1] Das, A.K. (2001). Kinetics and Mechanistic Aspects of Metal Ion Catalysis Ce(IV) Oxidation. Coord. Chem. Rev., 213: 307-325.

[2] Agrawal, M.C., Upadhyay, S.K. (1983). Os(VIII) Catalyst in Some Redox Reactions. J. Sci. Ind. Res., 42: 508-517.

[3] Srivastava, S., Gupta, M. (2015). Osmium(VIII) Catalysed Oxidation of Leucine by Alkaline Sodium Periodate: A Kinetic Study. Bulletin of Catalysis Society of India, 14: 1-5.

[4] Tuwar, S.M., Nandibewoor, S.T., Raju, J.R. (1991). Os(VIII) Oxidation Of Chromium (III) in Aqueous Alkaline Medium. Indian J. Chem, 30A: 158-161.

[5] Day, M.C., Selbin, J. (1964). Theoretical Inorganic Chemistry, 2nd eds. Van NustrandReinhold: New York, p. 138.

[6] Morab, V.A., Tuwar, S.M., Nandibewoor, S.T., Raju, J.R. (1992). Os(VIII) Catalysed Oxidation of Allyl alcohol by HCF(III) in Alkaline Medium. J. Indian Chem. Soc., 69: 862-864.

[7] Tuwar, S.M., Nandibewoor, S.T., Raju, J.R. (1991). Os(VIII) Oxidation of Arsenic(III) in Aqueous Sulfuric Acid. Trans. Met. Chem., 16: 196-199.

[8] Srivastava, S., Prajapati, D. (2016). Kinetic and Thermodynamic Aspects of Os(VIII) catalysed Oxidation of L-Leucine by Ferrate in Alkaline Medium. Bulletin of Catalysis Society of India, 15: 3-4.

[9] Mahadevappa, D.S., Rangappa, K.S., Gowda, N.N.M., Thimmegowda, B. (1986). The Kinetics of Oxidation of L-Proline bt DPC(III) in Aqueous Alkaline Medium. Int. J. Chem. Kinet., 60: 589-593.

[10] Rennie, J.M., Washington D.C. (1999). National Academy Press, p. 243-246.

Table 2. Thermodynamic activation parameters for the oxidation of L-alanine by sodium periodate catalysed by Osmium (VIII) in alkaline medium.

\begin{tabular}{|c|c|c|c|}
\hline \multicolumn{4}{|c|}{ Thermodynamic activation parameters } \\
\hline \multicolumn{4}{|c|}{ Reaction for oxidation of L-alanine } \\
\hline Temperature (K) & $10 \mathrm{k}\left(\mathrm{sec}^{-1}\right)$ & $\log \mathrm{A}$ & 11.73 \\
\hline 303.0 & 1.84 & $\mathrm{Ea} /\left(\mathrm{KJ}_{\mathrm{mol}} \mathrm{mol}^{-1}\right)$ & 41.58 \\
\hline 308.0 & 2.49 & $\Delta \mathrm{H}^{\# /\left(\mathrm{KJ} . \mathrm{mol}^{-1}\right)}$ & 40.18 \\
\hline 313.0 & 3.46 & 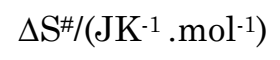 & -5.79 \\
\hline 318.0 & 4.42 & $\Delta \mathrm{G}^{\# /\left(\mathrm{KJ}_{\mathrm{mol}}{ }^{-1}\right)}$ & 38.39 \\
\hline
\end{tabular}


[11] Pascual, R., Miguel, A.H., Callie, E. (1989). Kinetics and Mechanism of Oxidation of Proline by Periodate. Can. J. Chem., 67: 634638.

[12] Pascual, R., Herraez, M.A. (1985). The Mechanism of the Oxidative Deamination and Decarboxylation of Serine and Threonine by Periodate in Acid Medium. Can. J. Chem., 63: 2349-2353.

[13] Veerasomaiah, P., BalReddy, K., Sethuram, B., Navaneeth Rao, T. (1987). Indian J. Chem., 26A: 402-406.

[14] Saxena, O.C. (1967). New Titrimetric Microdetermiation of Osmium. Microchem J., 12: 609-611.

[15] Feigl, F. eds. (1975). Spot Tests in Organic Analysis. Elsevier: New York, p. 58.

[16] Jeffery, G.H., Bassett, J., Mendham, J., Denny, R.C. (1996). Vogel's Textbook of Quantitative Chemical Analysis. 5th eds. ELBS Longman: Essex UK, p. 455.

[17] Vogel, A.I. (1973). A Text Book of Practical Organic Chemistry Including Quantitative Organic Analysis, $3^{\text {rd }}$ eds. ELBS Longman: Essex UK, p. 332.

[18] Bailar, J.C., Emeleus, H.J., Nyholm, S.R., Trotman-Dikenson, A.F. eds. (1975). Comprehensive Inorganic Chemistry. Pergamon Press: Oxford, p. 1456.
[19] Sethuram, B. eds. (2003). Some Aspects of Electron Transfer Reactions Involving Organic Molecules. Allied Publishers (P) Ltd.: New Delhi, p. 78.

[20] Kiran, T.S., Hiremath, D.C., Nandibewoor, S.T. (2007). Oxidation of Paracetamol Drig by Periodatocuperate(III) in Aqueous Alkaline medium by Stop Flow Technique. Z. Phys. Chem., 221: 501-512.

[21] Chang, R. eds. (1981). Physical Chemistry with Applications to Biological Systems. Macmillan: New York, p. 326.

[22] Kamble, D.L., Nandibewoor, S.T. (1998). $\mathrm{Os}(\mathrm{VIII}) / \mathrm{Ru}(\mathrm{III})$ Catalysis of Periodate Oxidation of Acetaldehyde in Aqueous Alkaline Medium. J. Phys. Org. Chem., 11: 171-176.

[23] Vemulapalli, G.K. eds. (1997). Physical Chemistry. Prentice-Hall, Inc.: England Cliffs, N.J, U.S.A, p. 734.

[24] Farokhi, S.A., Nandibewoor, S.T. (2003). Kinetic, Mechanistic and Spectral Studies for the Oxidation of Sulfanilic Acid by Alkaline HCF(III). Tetrahedron, 59: 7595-7602.

[25] Sridevi, N., Annapurna, N., Vani, P. (2015). Mechanism of Osmium(VIII) Catalysed Oxidation of L-Arginine by Periodate in Alkaline Medium - A Kinetic Study. Chemical Science Transactions, 4(2): 552-558 


\section{Appendix: Derivation of Rate Law for Scheme 1}

$\left[\mathrm{Os}(\mathrm{VIII})_{\mathrm{T}}\right]$ is equal to sum of concentration of,

$$
\begin{aligned}
& \frac{d\left[\mathrm{IO}_{4}^{-}\right]}{d t}=\text { rate }=k_{3}\left[\mathrm{IO}_{4}^{-}\right][\text {Complex }] \\
& \text { Os }(\mathrm{VIII})_{T}=\left[C_{1}\right]+\left[\mathrm{C}_{2}\right]+\left[\mathrm{C}_{3}\right] \\
& \frac{d\left[C_{1}\right]}{d t}=-k_{1}\left[C_{1}\right]\left[\mathrm{OH}^{-}\right]+k_{-1}\left[C_{2}\right]-k_{2}\left[C_{1}\right][L-\text { ala }]+k_{-2}\left[C_{3}\right]
\end{aligned}
$$

On applying steady state approximation to equation (7) we get,

$$
\left.-k_{1} C_{1} \mid O H^{-}\right\rfloor+k_{-1}\left[C_{2}\right]-k_{2}\left[C_{1}\right][L-\text { ala }]+k_{-2}\left[C_{3}\right]=0
$$

Similarly we have rate of formation of $\left[\mathrm{C}_{2}\right]$,

$$
\frac{d\left[\mathrm{C}_{2}\right]}{d t}=k_{1}\left[\mathrm{C}_{1}\right]\left[\mathrm{OH}^{-}\right]-k_{-1}\left[\mathrm{C}_{2}\right]
$$

On applying steady state approximation to the above equation we get,

$$
\begin{aligned}
& k_{1}\left[C_{1}\right]\left[\mathrm{OH}^{-}\right]-k_{-1}\left[C_{2}\right]=0 \\
& {\left[C_{2}\right]=\frac{k_{1}\left[C_{1}\right]\left[\mathrm{OH}^{-}\right]}{k_{-1}}}
\end{aligned}
$$

From equations (8) and (10) we get,

$$
\left[C_{1}\right]=\frac{k_{-2}\left[C_{3}\right]}{k_{2}[L-a l a]}
$$

Putting the value of $\left[\mathrm{C}_{1}\right]$ in equation (11) we get,

$$
\begin{aligned}
& {\left[C_{2}\right]=\frac{k_{1} k_{-2}\left[\mathrm{OH}^{-}\right]\left[C_{3}\right]}{k_{-1} k_{2}[L-a l a]}} \\
& {\left[C_{2}\right]=\frac{K_{1}\left[\mathrm{OH}^{-}\right]\left[C_{3}\right]}{K_{2}[L-\text { ala }]}\left\{\because K_{1}=\frac{k_{1}}{k_{-1}} ; K_{2}=\frac{k_{2}}{k_{-2}}\right\}}
\end{aligned}
$$

Therefore from Equations (6), (12), and (13), we get total concentration of catalyst, i.e.,

$$
\begin{aligned}
\text { Os }(\text { VIII })_{T} & =\frac{\left[C_{3}\right]}{K_{2}[L-a l a]}+\frac{K_{1}\left[\mathrm{OH}^{-}\right]\left[C_{3}\right]}{K_{2}[L-\text { ala }]}+\left[C_{3}\right] \\
& =\frac{\left[C_{3}\right]}{K_{2}[L-\text { ala }]}+\frac{K_{1}\left[\mathrm{OH}^{-}\right]\left[C_{3}\right]}{K_{2}[L-\text { ala }]}+\left[C_{3}\right] \\
& =\left[C_{3}\right]\left\{\frac{1+K_{1}\left[\mathrm{OH}^{-}\right]+K_{2}[L-\text { ala }]}{K_{2}[L-\text { ala }]}\right\} \\
{\left[C_{3}\right] } & =\left\{\frac{K_{2}[L-\text { ala }]\left[\mathrm{OS}_{\left.(\mathrm{VIII})_{T}\right]}\right.}{1+K_{1}\left[\mathrm{OH}^{-}\right]+K_{2}[L-\text { ala }]}\right\}
\end{aligned}
$$


Therefore, from Equations (5) and (14) we get,

$$
\text { Rate }=\left\{\frac{k_{2} K_{2}\left[\mathrm{IO}_{4}^{-}\right]\left[\mathrm{Os}(\mathrm{VIII})_{\mathrm{T}}\right][L-\text { ala }]}{1+K_{1}\left[\mathrm{OH}^{-}\right]+K_{2}[L-\text { ala }]}\right\}
$$

The rate law is in agreement with all observed kinetics. 